A publication of the Muma College of Business | University of South Florida

Volume 3

Number 15

31 DEC 2018

YAKOMBA YAVWA

\title{
EFFICIENT TAX SYSTEM IN ZAMBIA ${ }^{1}$
}

A robust tax administration information system that has capabilities of providing timely and accurate management information is a key ingredient of running a successful and wellfunctioning tax administration.

Mr. Berlin Msiska, the CEO for the Zambia Revenue Authority (Tax Administration), was wondering how return on investment (ROI) might be used to assess investments in ICT intended to improve the efficiency and effectiveness of the country's tax system.

At a TADAT (Tax Administration Diagnostic Assessment Tool) public release international conference, Mr. Msiska underscored the need for a robust tax system that ensured ROI. Mr. Msiska was invited as a guest speaker at the conference in Washington where the tool was officially launched. His statement clearly underpinned the role of ICTs in the transformation agenda.

Mr Msiska further believed that ICTs had transformed service delivery in governments, in particular in the Zambia Revenue Authority. Governments were strategically positioned and proactive to the needs of the citizens partly due to the adoption (Kumar et al. 2007) of ICTs. The effectiveness of service delivery in government was anchored on effective use of technology.

The enhancements in technology provided a further platform for collaboration within government. There was a shift towards shared services. The harmonisation of policy, legal and institutional frameworks presented an opportunity to enhance service delivery. Open government data (OGD) was another philosophy that was built on this collaboration and harmonisation for the social well-being of the citizens. The OGD philosophy depended on the capacity of the government agencies to generate huge amounts of data. Proper harnessing, management and use of such data would help in the segmentation of stakeholders that require services from government institutions. This would in turn contribute to government's ability to deliver services efficiently. The OGD philosophy was also useful for the Tax Administration in that it provided an electronic platform that integrated with tax systems. As well as increasing processing efficiencies, the integration enabled the tax systems to capture more transactions. The resultant effect was an increase in revenue collections.

The critical decision being faced was "How can the ROI of tax systems be computed and should we advocate using ROI?”

\footnotetext{
${ }^{1}$ Copyright $($ C 2018, Yakomba Yavwa. This case was prepared for the purpose of class discussion. Names and some information have been disguised. This case is published under a Creative Commons BY-NC license and originally appeared as a chapter in Transforming Society Using ICT: Contemporary Discussion Cases from Africa. Permission is granted to copy and distribute this case for non-commercial purposes, in both printed and electronic formats.
} 


\section{Zambia}

Zambia was a land locked country located in Southern Africa, see Exhibit 1. It had a land mass of 752,612 square kilometres and a population of 13,092,666 (Zambia 2012) predominantly comprised of 73 tribes. The Gross Domestic Product (GDP) in Zambia was 27.07 billion US dollars in 2014 (Husna 2015).

The ICT sector of Zambia had achieved a remarkable development during the past decade with major reforms. Among the key governmental actions that facilitated this development:

- The national ICT policy was formulated and approved in 2006. This policy was developed to provide guidance in the implementation of ICT Services in 13 domains. These included Education, Health, Agriculture, Human Resource, Multimedia, E-Government, E-Commerce, Telecommunication Infrastructure, ICT Sector, Tourism, Youth and Women, Legal and regulatory framework, and the ICT Security domain.

- The Electronic Communication and Transactions Act Number 21 of 2009 was also enacted by Parliament. This piece of legislation provided guidance for all electronic communications and electronic transactions. Before this act, electronic evidence was not admissible in court.

- The Computer misuse and crimes Act of 2004 was enacted by Parliament. Prior to this act, there was no basis for prosecuting people that were guilty of computer related crimes.

- The Information and Communication Technologies Amendment Act number 15 of 2009 was also enacted by Parliament. These legislative changes were made to prepare ground for modernisation programmes in the country.

Zambia's ICT sector recorded a high penetration rate of 32 percent by 2015 compared to only 0.02 percent growth in 2001. Despite these impressive figures, access to internet and mobile services was limited to less than $5 \%$ and $30 \%$ of the population of Zambia respectively. The paradox of this was that individual institutions had recorded transformational changes in the Socio-Technical space. Among a few government ministries and departments that experienced greater transformation in relative terms was the Tax Administration. This transformation was largely aided by the pressure for electronic services (eServices), a push driven initiative.

The ICT infrastructure in Zambia was further enhanced when telecommunication companies laid transnational optic fibre links. One such company was the CEC Liquid that had optic fibre running from South Africa through Zimbabwe, Zambia and into Congo DR. This presented an opportunity for the country to implement high speed ICT solutions that transformed the perspective of government. The existence of a transcontinental optic fibre from Namibia to America and also to Europe presented Zambia with an opportunity to interconnect for efficient internet provision.

\section{Services Delivery Model}

Exhibit 2 shows a taxonomy of outputs that formed a delivery system within Government. Such a delivery system reduced or eliminated queues at government service delivery points and enabled stakeholders to enjoy better levels of services through online transparent transactional facilities void of human interventions. Exhibit 2 is an example of an e-Services philosophy that had proved to be a fundamental engine for transforming governments.

The illustration in Exhibit 2 shows how a successful implementation of such eServices delivery sub systems and their integration was key for a functional Government system anchored on ICT (Beynon- 
Davies 2007). Zambia, whose e-Government Development Index rating was below 0.25, was not yet at the point of attaining such an implementation. However, the country was making steady progress in this area. Based on the United Nations e-Government survey of 2014 (UN 2014), the world's average eGovernment Development Index was rated at 0.4712 with the highest being the Republic of Korea at 0.9462 .

\section{Tax Regimes in Zambia}

The Tax Administration was a government department charged with the responsibility of collecting taxes on behalf of the government of the republic of Zambia. In Zambia, many institutions were responsible for collecting non-tax revenues, most of which were fines. These included the Zambia Police, Road Traffic and Safety Agency, Patents and Company Registration Agency, and Road Development Agency, to mention a few. The Tax Administration was the only institution that collected taxes and duties. These taxes included Income Taxes (Corporate Tax, Pay-As-You-Earn, Turn over Tax, Withholding Tax), Property Transfer Tax, Mineral Royalty, Presumptive Tax, Base Tax, Import duties, Excise, Value Added Tax, and Export duties. The Income Taxes were on a self-assessment regime while the duties were assessed and valued by the Tax Administration.

Tax policy was administered by the Ministry of Finance, which was the controlling ministry. The Tax Administration executed the Tax Policy. Although the Tax Administration was the executing agency, it made legislative proposals that were submitted to the Ministry of Finance for consideration.

\section{Before automation}

The Tax Administration, like many companies in Zambia, was largely operating in a manual environment until the late 90s. Different manual forms were used to process different functions. For example, the PayAs-You-Earn (PAYE), a form of Income Tax, employed two types of forms: P16 and P18. P16 was a manual monthly return used for monthly PAYE remittance. The P18 was an annual return that summarized the tax activity for the year. For other types of Income Tax, Income Tax Form 302 was used. VAT 100 tax return was used to account for domestic VAT while VAT 200 was used to account for import VAT at the borders or Customs Ports. CE 21 was used as a return to declare imports at the borders or Customs Ports and excise.

The process of completing these forms, carrying out assessments and valuations was tedious. It took several days to complete a tax process. The effect of these inefficient procedures was an increase in the cost of doing business in Zambia. Automation, to guarantee the desired returns on investment, seemed to be the only option. Other challenges included long queues at service counters. There was also a lack of self-service functionality on the systems' portal to enable Taxpayers perform self-service. There were delays in refunds. The manual nature of transactions resulted in delays in credibility checks. The environment was ripe for tax evasion and non-compliance because of the loop holes inherent in manual systems. The Tax Administration information was largely inaccurate. Manual processing of returns and tracking of defaulters were strenuous activities. Real time data was unavailable to aid in timely decisionmaking. There was no integrated view of a taxpayer. Document tracking was time consuming.

Accounting in a predominantly manual environment was a challenge. Most of the processes and data were redundant. Due to poor records, it was difficult to communicate with taxpayers. The cumulative effect of all these variables was a high cost of tax collection on the part of the Tax Administration and high cost of compliance on the part of the citizen. 


\section{Initial stages of automation}

In the early $21^{\text {st }}$ Century, the millennium year, a tax administration system called Integrated Tax Administration System (ITAS) was implemented. This was in addition to the Customs systems called ASYCUDA 2.7 (A SYstem for CUstoms DAta) that had been implemented in the late 1990s and upgraded at the beginning of the $21^{\text {st }}$ Century to ASYCUDA++. These systems served their purpose at the time. With increased demand for e-Services, these systems could no longer provide a services delivery platform that met current needs. They were not fully functional. They were not web based. The transactions and processes were semi manual. The justification to replace these systems and the choice of the new systems were two key decision points. Well-articulated papers were prepared for the governing Board, who endorsed the need to replace the systems. The question was, "have we realized the returns on investment?” As CEO, this was not easy to quantify-especially inasmuch as optimization work to actualize the full potential benefits of the ITAS system was still being done. The decision at this point was binary (meaning "either-or")! It was then a choice between: a) continuous improvements in a domain to which users had already migrated philosophically and b) implementing a new system that met the dynamic needs of the users. The latter was option was perceived to be both socially and technically beneficial.

The overall objective was to implement a computerized tax management and information system that was efficient, effective and user friendly. Among others, its goals were:

- central control and monitoring of performance of the taxes,

- increased ability to access information on taxpayer and operational performance,

- increased internal controls to prevent and detect potential and actual fraud,

- online submission of returns commonly referred to as e-filing,

- improved long term planning through the provision of valuable information,

- $\quad$ ability to enable taxpayers to undertake self-assessment, and

- increased ability to demonstrate accountability and transparency to the public and cooperating partners.

Other fundamental drivers that skewed the decision towards modernization were the need to:

- assess and collect taxes equitably and fairly under the law;

- maximize voluntary compliance;

- $\quad$ predict non-compliance with greater ease and accuracy;

- increase revenue collected from non-filers and those concealing taxable transactions;

- increase flexibility in Tax Administration;

- easily exchange data internally and with strategic business partners;

- improve collaboration with partners; and

- improve quality of customer service for filing returns, making payments, requesting for refund and submitting appeals in terms of speed, accessibility, convenience, transparency and security through provision of e-Services.

As dictated by corporate governance, a formal process to replace and decommission these systems was undertaken. Using formal methods, functional requirements that would suit the dynamic needs of the business were developed. The functional requirements for the new tax administration system were subjected to peer review by a mission from the International Monetary Fund (IMF), who endorsed them. The International Competitive Bidding (ICB) tender process was followed in selecting a replacement system for ITAS. On the other hand, a decision to replace ASYCUDA++ with either a completely new system or upgrading it with a new ASYCUDA product had to be made. This decision was not trivial 
considering that the new proposed product required an ICT infrastructure that was characterized by stable and high link capacities. Zambia did not have such a robust infrastructure. However, there were plans to deploy optic fibre by CEC Liquid and also by the local Electricity Supply Company. This knowledge was fundamental in the decision to upgrade the ASYCUDA++ to ASYCUDAWorld. The good support relationship with UNCTAD, the suppliers of the application, supported the decision.

\section{Acquisition of the applications - the tendering process in detail}

In the Tax Administration, all procurements followed a prescribed tender process. This process was either the World Bank procurement process or the Zambia Public Procurement Authority (ZPPA) procurement process. If the procurements were funded by the donors, the World Bank procurement process would be applied up to approval stage. Once approval was obtained from the World Bank, authority would also be obtained from ZPPA. For procurements fully funded by the government of Zambia, authority would only be obtained from ZPPA. The tender would then be advertised after this approval.

In the context of the above stated systems, the process began with the User department clearly specifying the functional requirements. A workshop to develop these requirements was held to which key functional officers were invited. $90 \%$ of the participants were functional users. Information Technology Officers accounted for only $10 \%$ of participants. This was in line with the recommendations outlined by ISACA's COBIT framework (De Haes et al. 2013) in which information and communication technology was viewed as an enabler. The business sets strategic objectives and direction.

The requirements were subjected to several peer review mechanisms at different workshops by different functional users. These were functional experts representing different domains. The requirements were also subjected to review by internal audit to ensure that controls were sufficiently specified. The final review was conducted by an IMF mission to ensured that the requirements were futuristic. Authority was then sought from the ZPPA to advertise the tender, which was granted.

Due to the magnitude of this procurement, international competitive bidding was used. This method allowed foreign companies to participate in the tender process. National competitive bidding was only restricted to local (Zambian) companies. The tender was advertised in both the local and international media.

For TaxOnline, Six (6) bids were received. Most of these offered different solutions. Only two sets of bidders offered similar products. The variation in pricing structure, illustrated in Exhibit 3, was comparatively high.

It was interesting to note the variations in bid sums even when some of the bidders were proposing to implement the same product. Of interest were the delivery periods, some of which appeared to be unrealistic from a technical standpoint. The message in these statistics was that the requirements needed to be as clear as possible and a thorough evaluation conducted to ensure that the value proposition for the desired project was achieved.

The project sponsor appointed an evaluation committee to subject the bids to an adjudication process. This process involved preliminary, technical and financial evaluation. The preliminary evaluation was a mere check of compliance of the bidder, such as authority to resale proposed products (manufacturer's authorization), documents being properly signed (power of attorney), compliance with the tax obligations for local companies (Tax Clearance Certificate) to mention a few. In some cases, the preliminary 
evaluation was combined with the technical evaluation. Some of the elements that were considered included conformity to requirements, relevant experience, appreciation of the task, past performance, management and technical skills, company’s financial standing, similar projects, methodology, and price.

Generally, there were two common types of bid evaluation methods; weighted average and straight line evaluation techniques illustrated in Exhibit 4.

For the Tax Administration, weighted average was only used for quality and cost based selection criteria applied to consultancy services only. Since this procurement involved goods and services, the straight line evaluation technique was used.

From the six (6) bids that were received, only two were responsive. These were then subjected to the financial evaluation. The first step was to assess the completeness of the financial information provided after which the figures would then be compared. Unfortunately, one of the two bidders provided insufficient financial data. The remaining bidder therefore became the winning bidder.

For ASYCUDAWorld, the tendering process was not as laborious as the one for TaxOnline. UNCTAD, the supplier of ASYCUDA++ had released an upgrade. The new product was called ASYCUDAWorld. It was easier for the Tax Administration to justify to ZPPA to single source (also called direct bidding) than it was for the supply of TaxOnline. The only issue was contract negotiation which had to be managed.

"Project implementation dilemma! How we managed to fit complex projects into the creativity maze”

\section{Automation - Web Based Systems}

The implementation of the selected systems became a major activity for the Tax Administration. The two systems were among several projects being implemented as part of the modernization programme. The modernization programme was a portfolio of several projects. The major projects were the TaxOnline and ASYCUDAWorld. Other projects in the portfolio were the SharePoint, Case Management and Electronic Records Management systems. The diverse needs of these projects in terms of project governance, resources, skills and inter project relationships created complexities requiring critical decisions to be made at various points. This presented a creativity maze scenario that required people with high levels of intrinsic motivation. Luckily, the CEO, who was at the helm of this modernization programme, was one such person.

For the TaxOnline project, the key issues to be addressed in the creativity maze were project governance, payment schedule, offshore/onshore development strategy, technical and user training, source code vs. escrow, database access by the Tax Administration staff without going through the TaxOnline system for administrative purposes, software release controls and management of upgrades, hardware compatibility, acceptance sign off, data migration, correctness of blueprints, and Intellectual Property rights. The effective resolution of these issues was aimed at addressing the key question, "How can the ROI of tax systems be computed and should we advocate using ROI?”

Regarding project governance, there was recognition that most projects failed due to bad or lack of project governance practices. To address this, a project management department that coordinated all projects in the institution was created. This department was managed at the director level. A project governance policy was developed and a structure to manage all projects was created. The project sponsor was the chief executive, who was supported by a steering committee. Each project had a project owner, who chaired a Project Management Committee (PMC). The PMC consisted of senior staff in the department where the project was being implemented. The Director of Information Technology was a 
default member of all PMCs that had ICT related projects. Exhibit 5 shows the project governance specific to this institution.

Project work plan and schedule were key elements in any project. Agreeing to realistic and measurable milestones was important because payments were eventually aligned with these deliverables. The decision of onshore vs offshore development of the solution was non-trivial. In order to minimize costs, any solution provider of an application would opt for offshore development but this option would deprive the institution of onsite hands-on skills transfer. The strategy of application implementation needed to be driven by the value proposition to the institution. The CEO desired that the two applications be developed at the head office. This meant that the contractor would have to deploy their staff within the Tax Administration's project offices. The motivation for this requirement was the development of local capacity. For the implementation of ASYCUDAWorld, the development of the product was done at the Tax Administration project office. The blending of UNCTAD consultants and local developers in one development office (Project Office) was a ripe environment for skills transfer. The case was different for TaxOnline, which had many developers based offshore and developing specific components of the application. The trade-off was that $30 \%$ of development work would be done onshore and $70 \%$ done offshore. To compensate for the loss in skills transfer, it was mutually agreed that the technical team would join the offshore development team and undergo training.

Another complex scenario was ownership of the source code. Whereas the requirements specified the full ownership of the system, including source code, once purchased, the supplier cited intellectual property rights on the source code. An escrow agreement and a support and maintenance agreement was developed and was deemed acceptable to both parties.

Although the implementation of ASYCUDAWorld appeared to have been successful, there were undercurrents that had to be overcome. Before the system went live, everything appeared to be under control. Out of the planned 28 stations, three were selected as pilot sites so that potential challenges could be easily managed. On go live, the experience was shocking. The system was hardly accessible by the pilot sites. They experienced bandwidth bottlenecks. In retrospect, it was a wise decision to have chosen only three pilot sites to start with. The response to this challenge was to upgrade the bandwidth on the three links from 2 Mbps to $6 \mathrm{Mbps}$. This measure significantly improved the connectivity to these pilot sites. However, another problem emerged. As more sites or offices were brought on board to use the new system, new challenges surfaced.

The first challenge related to issues involving the database structure. By way of explanation, any robust and reliable relational database needed to pass the ACID test. In this context, "A" stood for Atomicity, "C" stood for Consistency, "I" stood for Isolation and "D" for Durability. The property of Atomicity ensured that a transaction involving two or more discrete pieces of information committed either all pieces or none. Consistency ensured that a transaction either created a new and valid state of data, or, if any failure occurred, it returned all the data to its original state before the transaction was started. Isolation ensured that a transaction in process and not yet committed remained isolated from any other transaction. Finally, Durability ensured that committed data was saved by the system such that in the event of a failure and the system restarted, the data was available in its correct state. This ACID concept was also described in the Standard ISO/IEC 10026-1:1992, Section 4. These ACID properties were necessary for the robustness and reliability of a database. To guarantee this reliability, databases had a locking mechanism. If a write operation was initiated, the initiator would lock the table being updated and keep the handle to avoid more than one write operation on the same data set, which would violate the 
property of Isolation and Consistency. Once the write operation was complete, the lock handle was released for the next write operation.

It was the release of the handle activity that produced a major degradation in system performance. As more offices were connected to the new system, more transactions (i.e. read and write operations) occurred. Accompanying the growing transaction rate, the failure rate for the release of the handle increased. Once the release process failed, no transaction would be performed on the system. The interim fix was to restart the application server to clear the locks. The restart would take as long as 30 minutes or more to normalize the system. This would happen as many as 6 times in a day translating into more than 180 minutes of down time. This was deeply frustrating for businesses, the Tax Administration and government. Through consultative meetings and involvement of the providers of the application server software and the web based system, a need was identified to upgrade these platforms. The release of software upgrades, in which the software vender made modifications to lock handling algorithms, and eventual upgrade of these platforms turned out to be the remedy. Further optimization of the developed scripts was also done to make the system more efficient.

Staff retention was another challenge for the major projects. The officers that were on the two projects were highly trained on the respective applications and in Java programing. This enhanced their market value. As a consequence, five of the thirteen (13) Officers that had been trained to manage these applications resigned and got other jobs elsewhere. Sustainability of projects or systems was a real challenge that continued to pose a threat to the success of these applications. Although recruitment and retraining provided a remedy, the problem of staff sustainability on such big projects remained a challenge which could only be partly mitigated by entering into support and maintenance contracts with service providers.

\section{After automation}

The transformation that was triggered by these evolutionary systems, so called because the Tax Administration was the first government department to implement the e-Services delivery platform. Exhibit 6 shows efficiencies prior to and after modernization. These represented important non-financial contributors to return on investment.

Before implementing the stated web based systems, it took the Authority a maximum of three days to register a Taxpayer. It took thirty days to process a VAT refund, forty-five days to process an income tax refund, thirty days to process a Customs refund, two days to process a refund to petty importers that made Customs deposits. Further, it took one and half days to process a clean Customs Declaration to enable the importer pay for the goods being imported. A clean customs declaration was one that had all the required documents attached and lodged by a credible clearing agent. The above statistics were applicable in a semi manual environment.

The web based systems such as TaxOnline and ASYCUDAWorld had a provision for electronic registration (e-registration), e-filing, e-payment and other e-services accessed through the ZRA Web Portal. These enhanced service delivery. The taxpayer no longer required spending unproductive time at the Revenue Authority to file a return or queue to make payment. The statistics provided in Exhibit 6 were based on 19 transactions that were processed in different stations and border posts (ZRA Offices). On average, for an e-registration that had all relevant attachments, the process took an average of 20 minutes (0.014 days) to complete. The Customs declaration took an average of 0.89 days (about 21 hours). The actual processing through the system was effectively 30 minutes. The increased time was largely due to delays in paying for the goods by importers. The processing time for the refunds from claim submission to receipt of the money was largely affected by the appropriation of funds from Treasury, which was done once in a month. This process was still semi-automated. Effective use of ICT, 
in which the Refund module on TaxOnline at the Tax Administration would integrate with the Funds Management Module in SAP, could further improve this process-assuming that the workflow for funds release was also automated.

The uptake of electronic filing of returns by Taxpayers on TaxOnline began at a slower rate largely due to the slow adoption of ICT. A key decision to expand and enhance change management programmes was made. In addition, a consultant was engaged to develop and implement a communication strategy. With these interventions, by 2015, all taxpayers were filing VAT (Value Added Tax) returns electronically. About 98\% of taxpayers were filing the Corporate Income Tax (CIT) and Personal Income Tax (PIT) returns electronically. Turnover Tax (ToT) had the lowest uptake rate. By 2015, 78\% of the taxpayers were filing their tax returns electronically.

Exhibit 7 is a graph that shows e-filing progression on TaxOnline from the go live date in October 2013 to 2015. The gained efficiencies underscore the transformation in government triggered by ICTs. These ICT enabled e-Services contributed to the transformation of government in Zambia.

The implementation of e-Services for the Tax Administration was not easy, in particular e-Payments. These were dependent on the cooperation from external parties. As of March 2016, out of the 16 Commercial Banks in the country, ten (10) had gone live on TaxOnline and ASYCUDAWorld e-Payment platforms.

Exhibit 8 shows that the electronic transactions for registration and return filing were progressing well. There were more electronic transactions in that domain than manual transactions. Eventually, as internet growth in the country reached maturity, it was expected that all transactions would be electronic. The uptake progression in the e-Payment domain was slow. The payment systems in the country were not fully developed. There were companies that provided online payment systems or point-of-sale payment systems. These electronic payment systems provided a platform to pay for goods or services electronically, instead of using cash or check, in person or by mail. Electronic payment systems were generally classified into four categories: credit card and debit cards; electronic cash; micropayment systems; and session-level protocols for secure transactions. Local companies such as "543 Konse Konse" allowed merchants, customers and dealers to purchase electronic vouchers through a wide range of distribution channels. Another company, Kazang Zambia was a real-time automated banking application that credited clients' accounts. Zoona which provided electronic transfer services enabling consumers to send or receive money in Zambia and Zamlink, which provided an infrastructure for processing electronic transactions between banks and other financial institutions were mature technologies. Connecting all the players in the electronic transactions domain using an integration switch would provide the required payment infrastructure and make it easier for taxpayers. Some banks were still operating non-VISA compatible old technologies that rendered interfacing with modern technologies prohibitive. Others had no local control of their ICT infrastructure making it difficult to implement required interfaces. They depended on external vendors or international corporate branch networks for their automation needs. These complexities had been major factors in the slow progression in the uptake of e-Payment functionality.

\section{Benefits}

Notwithstanding the slow update of e-payment, Mr. Msiska noted that the implementation of TaxOnline and ASYCUDAWorld brought about benefits for the Tax Authority. The Taxpayer Identification Number which previously took an average of two days to generate, was now taking less than one hour. The 
taxpayer now had access to the tax ledger in real time. Initially, the taxpayer visited the Tax Administration multiple times but the automation reduced the visits to one. The time taken to process the refunds to exporters was reduced from 3 weeks to 7 days. Trend analysis and revenue projections were now done in real time. Tracking of Suspense Account and automatic movement of amounts from suspense to tax payer account was being done in real time. Calculating penalties and interest in a manual or semi manual environment was almost impossible. With automation, calculation of interest and penalty were now done in real time. It was now easier to track payments, outstanding debt and demand notices. Emailing various reminder notices, TPIN certificates, Notices and Acknowledgment Receipts to taxpayers via e-mail generated by the tax systems was now possible. Automatic calculation of future interest and penalty at the time of approval of Time to Pay Agreements (TPAs) could now be done in real time.

TaxOnline introduced efficiency gains to the institution. Whereas the taxpayer visited the Tax Administration many times before; to file a return, make payment, obtain a statement, register for taxes, submit objections and appeals, this was no longer necessary. These services were available through eServices as illustrated in Exhibit 9.

\section{Issues under Consideration}

\section{Can the taxation system approach be extended to other functional domains, such as transport?}

In order to answer this question, it was necessary to consider the modular view of the tax system, which were web based systems. They were modular by design. Each module had a specific task. All the modules were integrated. Taking ASYCUDAWorld as an example, it had a number of modules that included accounting, transit, manifest, brokers, licensing and query modules. The accounting module was similar to a billing module in a transport system. The transit module managed the entry and exit of trucks into and out of a country was also similar to the vehicle tracking module of the transport system. The broker module which was used to identify and provide access to clearing agents could be modeled in a similar manner to the transporters module in a transport management system. The licensing module in which clearing agents were registered would be similar to the registration module in the transport management system in which transporters would be registered. This basic illustration showed similarities between the tax System and the transport system. In terms of project management, it could be seen that both the tax system and any similar systems would have related risks at design, implementation and operational levels (Zeng \& Skibniewski 2013).

At design stage, ensuring that there was sufficient commitment and support at management level was key. The alignment of specifications to corporate objectives was another risk that related to project scope, which had to be managed. Deviations from the scope would lead to serious consequences such as scope creep resulting in loss of time and money driven by additional requirements or change in specifications. Skill was another major risk. It took considerable time to develop staff who could understand and manage the system. Maintaining such skill was critical. The governance approach applied in managing these risks would not only be limited to the Tax System but could be extended beyond the Tax System.

The choice of a project manager was critical for the success of the project. The project manager needed to have knowhow of the domain in which the system was being implemented. He or she also needed to have a strong character to manage the supplier for timely and quality deliverables. Technical risks had varying dimensions. Key among these was the correct scaling and sizing of the server hardware and link bandwidth.

The operational level had similar types of risks. These had more to do with sustainability of the systems both in the short and long term. These risks included management, technical and culture. The project governance approach adopted required that the systems had a maintenance plan, adequate policies 
governing the updates and upgrades, and a well-articulated support strategy. In any system, the growth of the data followed a Malthusian growth model. This called for proper sizing of the server and storage environments. Many change management sessions were held within the change management strategy to deal with cultural risks. If not properly managed, cultural risks could contribute to project failure (Scott \& Vessey 2002).

A system such as the transport management system would not be exempt from such risks. Inevitably, the project governance techniques applied in the tax system would be valuable tools for the success of any similar project.

The approach and methods applied were formal methods. In any functional domain or area where a new system was to be implemented, it was required that a clearly defined user requirements document was developed. This would serve as a basis for the services to be procured. The tendering process followed and the product selection was another critical step that required a lot of effort and attention.

Any other system such as transport management system, procurement system or human capital management system would need a well-defined governance framework as shown in Exhibit 5. It could be argued that this framework was a good candidate for other implementations. The use of this governance framework made the workflows self-regulating. This means that the various stages of project governance followed a pre-defined process. This increased the chances of success for any similar project.

Generally, it could be concluded that the approach used in the taxation system would be applicable to any other functional domain.

\section{Going Forward}

The question "How can the ROI of tax systems be computed and should we advocate using ROI?" is broad and therefore cannot receive a linear answer. From a quantitative perspective, Return on Investment (ROI) is computed by considering the net returns and the cost of investment. i.e.

$$
R O I \% \equiv \frac{(\text { Return }- \text { Investment } \cos t)}{\text { investment } \cos t} * 100
$$

This value was easier to compute for a private profit making firm. For a government institution such as the Revenue Authority, ROI would be based on other factors such as the revenue growth resulting from the investment, increased efficiencies resulting in reduced cost of compliance, ability of government to offer services to its citizens and many others. From a quantitative view point, one would affirm that the revenue increase may be used to compute the returns on investment. From a qualitative perspective, the variables were multidimensional. They ranged from the perceived performance of the system to the value proposition to the taxpayer.

In trying to examine the question of ROI, Mr. Msiska had been advised by the CIO that, from a technical standpoint, the two systems could be consolidated into one system. The consolidated system would then share a common database. This would contribute to the accuracy of the data which was a key measure in ensuring that taxpayers received credible assessments. A common database enabled such accuracy and ensured that system controls were applied across the integrated system although this could still have been achieved through efficient interfaces. Having one integrated system performing multiple functions 
provided more returns on investment. It reduced the number of servers or hardware resources and streamlined processes on the system and increased throughput.

ROI could not be discussed without considering the adoption of ICTs in government, a critical aspect for the overall transformation to take place. Mere adoption of these technologies was in itself not sufficient to attain the desired transformation agenda for government. Further, the components of the e-Services described in the two systems could easily be adopted and adapted to suit the needs of other government institutions to speed up the transformational process. How could all these factors be incorporated into an ROI methodology that could be applied to this and other ICT systems?

\section{References}

Beynon-Davies, P. (2007). Models for e-government. Transforming Government: People, Process and Policy, 1(1), pp.7-28. Available at: http://www.emeraldinsight.com/doi/abs/10.1108/17506160710733670

De Haes, S., Van Grembergen, W. and Debreceny, R.S. (2013). COBIT 5 and Enterprise Governance of Information Technology: Building Blocks and Research Opportunities. Journal of Information Systems, 27(1), pp.307-324. Available at: http://dml.regis.edu/login?url=http://search.ebscohost.com/login.aspx?direct=true\&db=bth\&AN=88 $181972 \&$ site $=$ ehost-live\&scope $=$ site.

Husna, R. (2015). Indonesia GDP Growth Weakest in 6 Years. http://www.tradingeconomics.com, pp.110. Available at: http://www.tradingeconomics.com/indonesia/gdp-growth-annual.

Kumar, V., Butt, I., and Ajax Persaud, A. (2007). Factors for successful e-government adoption: a conceptual framework. Electronic Journal of E-government, 5(1), pp.63-76. Available at: http://issuu.com/academic-conferences.org/docs/ejeg-volume5-issue1-article89.

Scott, J.E.and Vessey, I., (2002). Management Risks in Enterprise Systems Implementations, Communications of the ACM, 45(4), pp.74. Available at: http://0search.ebscohost.com.pugwash.lib.warwick.ac.uk/login.aspx\%3fdirect\%3dtrue\%26db\%3dedb\%26A N\%3d11863492\%26site\%3deds-live\&group=trial.

UN, 2014. UN E-Government Survey (2014). Economic \& Social Affairs. Available at: http://unpan3.un.org/egovkb/en-us/Reports/UN-E-Government-Survey2014\nhttp://unpan3.un.org/egovkb/Portals/egovkb/Documents/un/2014-Survey/EGov_Complete_Survey-2014.pdf.

Zambia, C.S.O. (2012). Census of population and housing 2010. National Analytic Report.

Zeng, Y.and Skibniewski, M.J. (2013). Risk assessment for enterprise resource planning (ERP) system implementations: a fault tree analysis approach. Enterprise Information Systems, 7(3), pp. 332-353. 


\section{Biography}

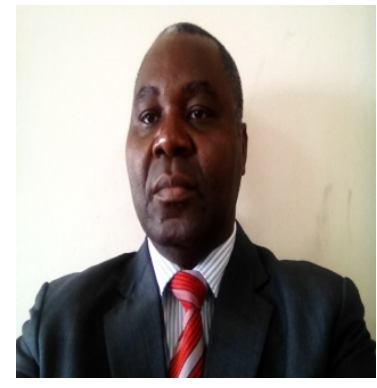

Yakomba Yavwa is a graduate of the University of Cape Town and University of Zambia where he obtained an MSc in Computer Science and BSc in Mathematics and Computer Science, respectively. He has worked mostly for the Zambia Revenue Authority as Director of ICT. He also worked as a Consultant for a government transformational project called IFMIS, which was sponsored by the World Bank and other Cooperating Partners. He is certified in the Governance of Enterprise Information Technology (CGEIT). 


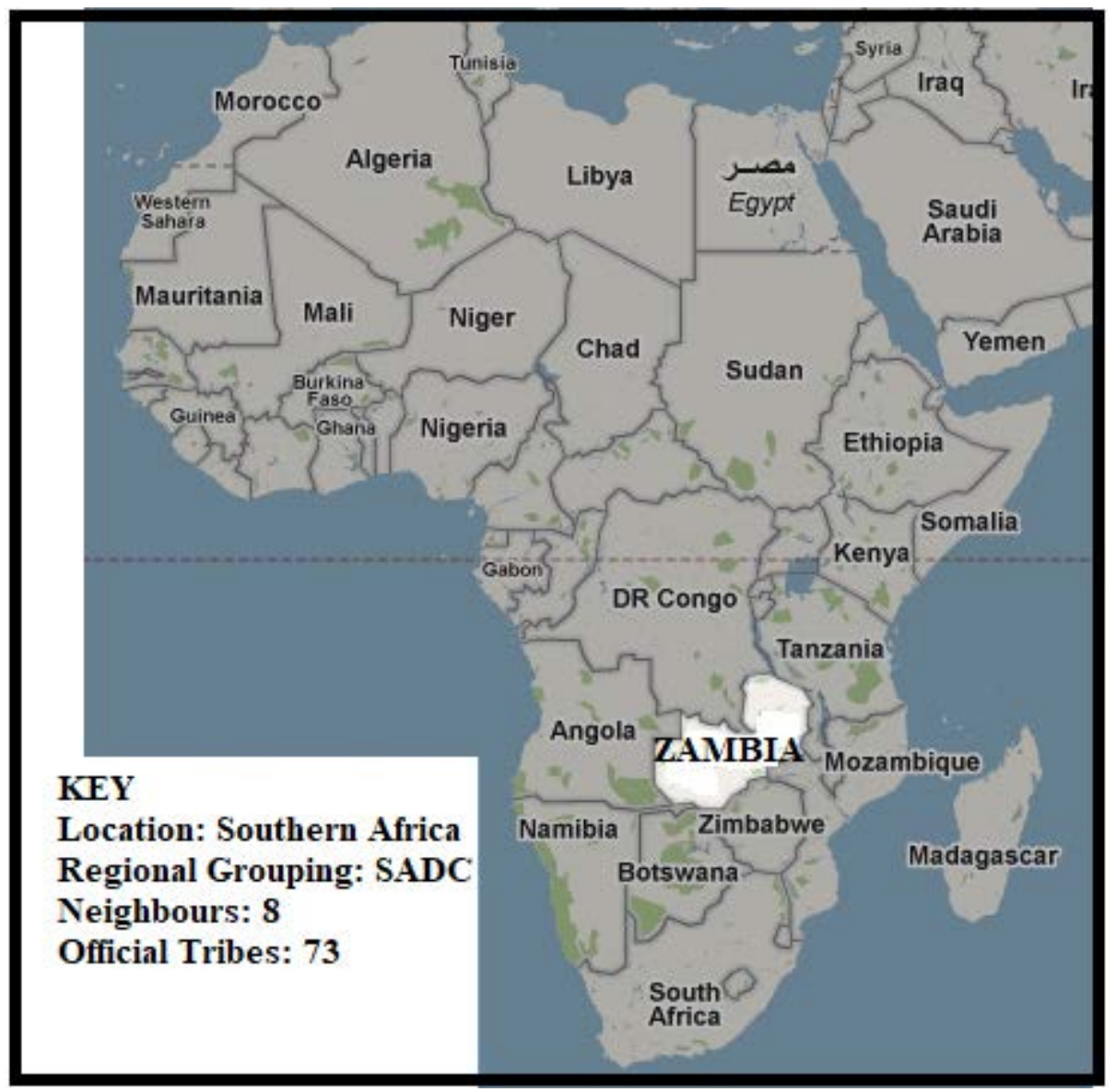




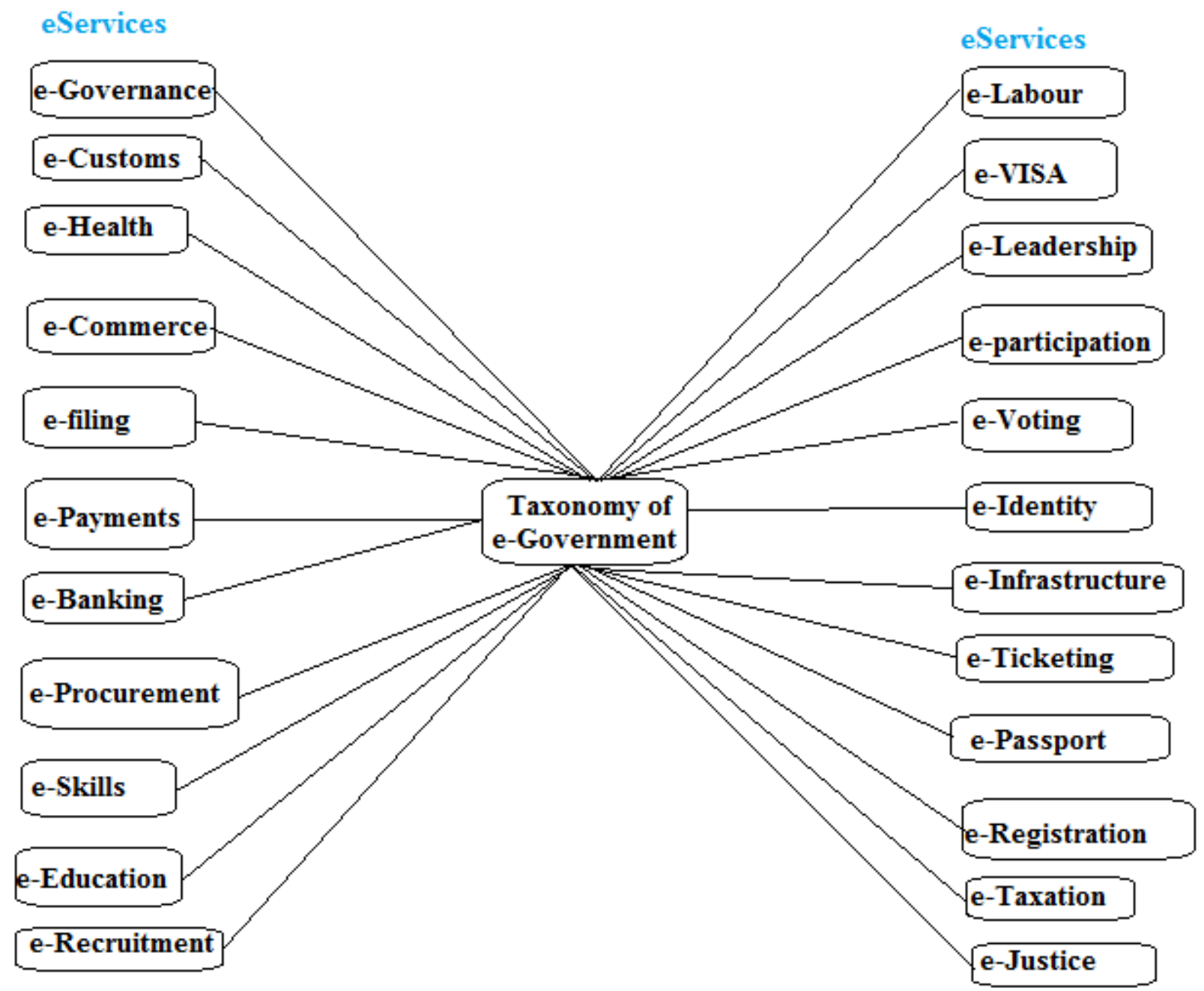




\section{Exhibit 3: Comparative pricing of ERP systems}

\begin{tabular}{|l|l|l|l|l|}
\hline $\begin{array}{l}\text { S/ } \\
\text { N }\end{array}$ & Bidder & Total Amount & Bid Security & Delivery Period \\
\hline 1 & A & USD11,000K less 16\% & X1 & 12 months \\
\hline 2 & B & Euro 900K less 16\% & X2 & 36 months \\
\hline 3 & C & USD 3,000K less 16\% & X3 & 6 months \\
\hline 4 & D & USD6,000K less 16\% & X4 & 2 months \\
\hline 5 & E & USD2,000K less 16\% & X5 & 14 months \\
\hline 6 & F & USD1,000K less 16\% & - & 5 months \\
\hline
\end{tabular}




\section{Exhibit 4: Tender Evaluation Techniques}

\section{Weighted Average}

The detailed technical score could be derived as follows;

$\mathrm{T}_{\mathrm{DE}}=0.3 \mathrm{~T}_{\mathrm{HI}}+0.3 \mathrm{~T}_{\mathrm{SP}}+0.4 \mathrm{~T}_{\mathrm{FS}}$ where, $\mathrm{T}_{\mathrm{DE}}=$ The Detailed Evaluation Technical score

$\mathrm{T}_{\mathrm{HI}}=$ The Technical score for Hardware/Infrastructure Requirements

$\mathrm{T}_{\mathrm{SP}}=$ The Technical score for Supplier Performance

$\mathrm{T}_{\mathrm{FS}}=$ The Technical score for the Functional Specification

The ratios 0.3 and 0.4 denote weights given to the specific components of the solution.

The financial evaluation score could also be derived as follows;

The Recurrent Costs (R) for Bid Price for all the phases could be reduced to net present value and determined using the following formula:

$$
R \equiv \sum_{x=1}^{N+M} \frac{R_{x}}{(1+I)^{X}}
$$

where

$$
\begin{aligned}
& \mathrm{N}=\text { number of years of the Warranty Period } \\
& \mathrm{M}=\text { number of years of the Post-Warranty Services Period } \\
& \mathrm{x} \quad=\quad \text { an index number } 1,2,3, \ldots \mathrm{N}+\mathrm{M} \text { representing each year } \\
& \text { of the combined Warranty Service and Post-Warranty } \\
& \text { Service Periods. } \\
& \mathrm{R}_{\mathrm{x}}=\quad \text { total Recurrent Costs for year “ } \mathrm{x} \text {," as recorded in the } \\
& \text { Recurrent Cost Form. } \\
& \text { I }=\text { discount rate to be used for the Net Present Value } \\
& \text { calculation }
\end{aligned}
$$

The combined bid evaluation would take into account the technical evaluation and the financial evaluation of the bids. The weighting factors for bid scores in the combined evaluation are as follows:

$$
S \equiv \frac{C_{\text {low }}}{C} X+\frac{T}{T_{\text {high }}}(1-X)
$$




\begin{tabular}{|c|c|c|}
\hline S & $=$ & Combined Bid Score \\
\hline $\mathrm{C}_{\text {low }}$ & $=$ & The lowest of all Weighted Evaluated Bid Prices \\
\hline $\begin{array}{l}\text { C } \\
\text { weighted) }\end{array}$ & $=$ & Weighted Evaluated Bid Price (Fixed cost + R, \\
\hline $\mathrm{X}$ & $=$ & Weight for the Price \\
\hline $\mathrm{T}$ & $=$ & The total Technical Points awarded to the bid \\
\hline $\begin{array}{l}T_{\text {high }} \\
\text { bid }\end{array}$ & $=$ & The highest Technical Points awarded to any responsive \\
\hline $1-\mathrm{X}$ & $=$ & Weight for the Bid Technical Score \\
\hline
\end{tabular}

\section{Straight line}

This technique required that the bidder met all the technical requirements specified in the tender document. The rating for each element was therefore "YES" or "NO". A "NO" rating on any element in the preliminary or technical evaluation would result in the bid being non responsive. 


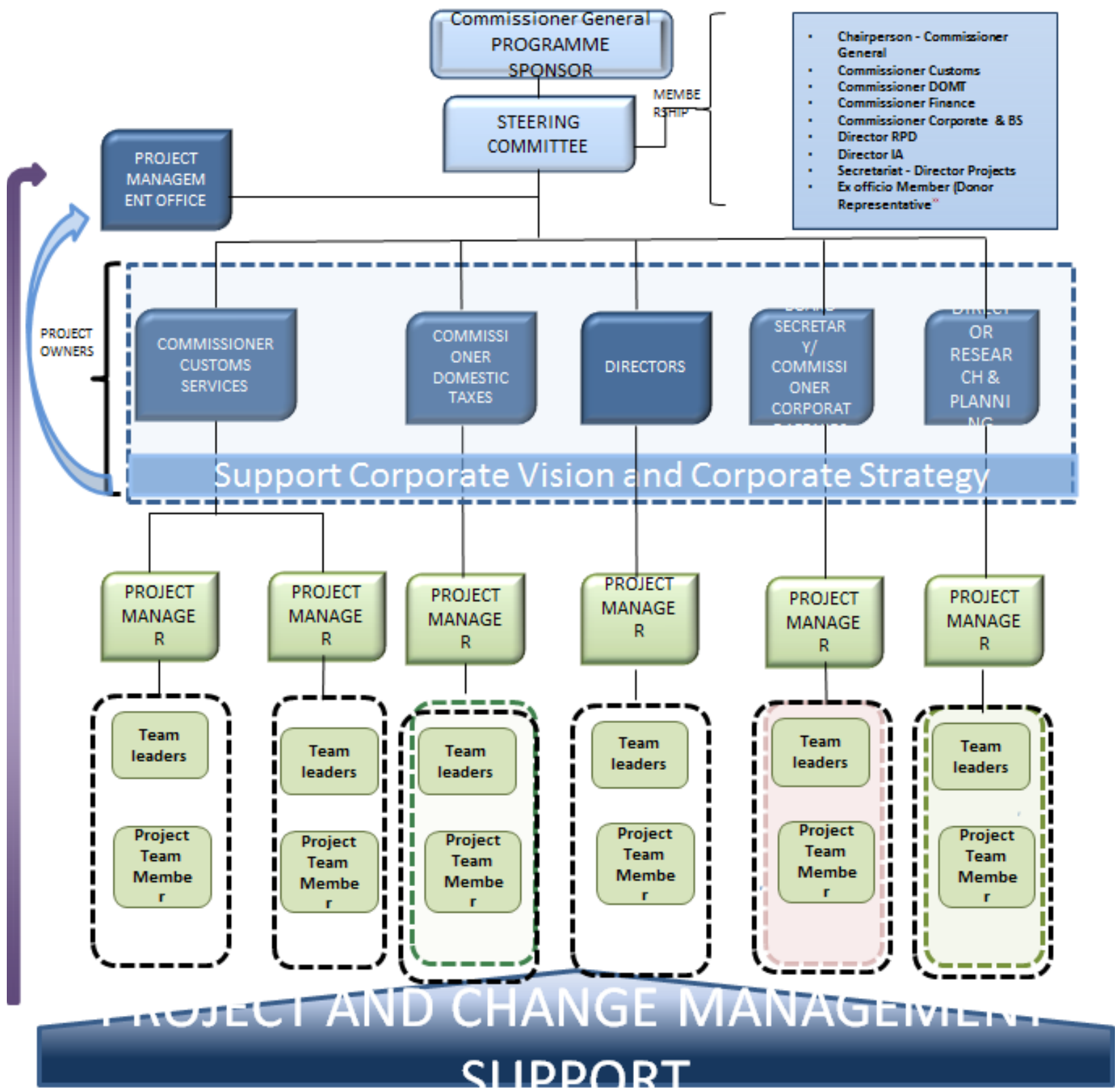

Source: Zambia Revenue Authority 


\section{Exhibit 6: The Taxpayer Charter prior to and after automation}

The Taxpayer Charter prior to web based automation

\begin{tabular}{|c|c|c|c|c|c|c|}
\hline $\begin{array}{c}\text { Nature of } \\
\text { Service }\end{array}$ & $\begin{array}{c}\text { Tax } \\
\text { Registration }\end{array}$ & $\begin{array}{c}\text { VAT } \\
\text { Refund } \\
\text { Tax Refund }\end{array}$ & $\begin{array}{c}\text { Income } \\
\text { Refund }\end{array}$ & $\begin{array}{c}\text { Customs } \\
\text { Deposit } \\
\text { Refunds }\end{array}$ & $\begin{array}{c}\text { Customs } \\
\text { Declaration }\end{array}$ \\
\hline $\begin{array}{c}\text { Duration } \\
\text { (days) }\end{array}$ & 3 & 30 & 45 & 30 & 2 & 1.5 \\
\hline
\end{tabular}

Processing efficiencies after web based automation

\begin{tabular}{|c|c|c|c|c|c|c|}
\hline $\begin{array}{c}\text { Nature of } \\
\text { Service }\end{array}$ & $\begin{array}{c}\text { Tax } \\
\text { Registration }\end{array}$ & $\begin{array}{c}\text { VAT } \\
\text { Refund }\end{array}$ & $\begin{array}{c}\text { Income } \\
\text { Tax Refund }\end{array}$ & $\begin{array}{c}\text { Customs } \\
\text { Refund }\end{array}$ & $\begin{array}{c}\text { Customs } \\
\text { Deposit } \\
\text { Refunds }\end{array}$ & $\begin{array}{c}\text { Customs } \\
\text { Declaration }\end{array}$ \\
\hline $\begin{array}{c}\text { Duration } \\
\text { (days) }\end{array}$ & 0.014 & 21 & 21 & 30 & 0.1 & 0.89 \\
\hline
\end{tabular}




\section{Exhibit 7: e-filing as a percentage of total returns}

\section{e-filing as a $\%$ of total returns}

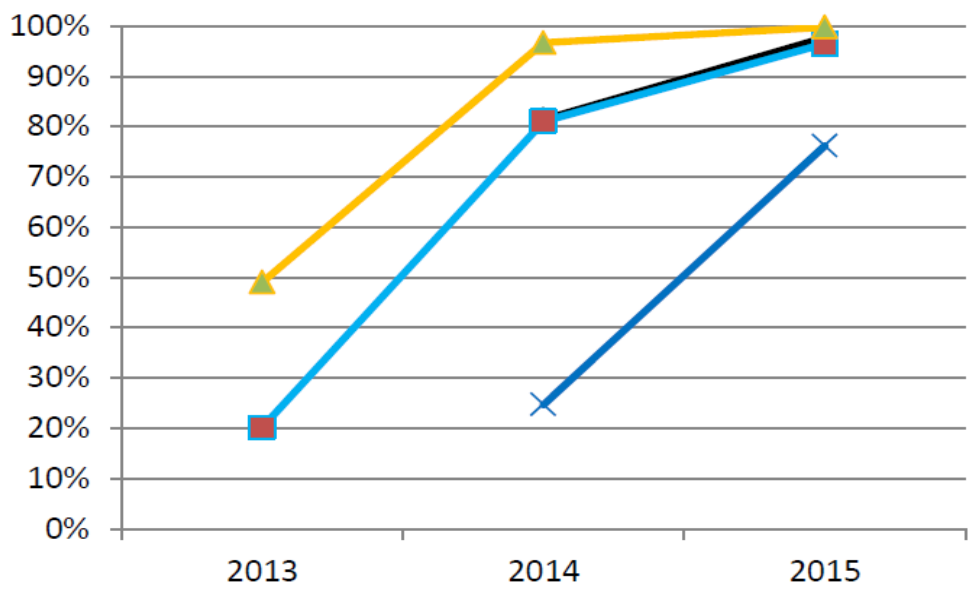

$\sim \%$ uptake on e-filing - CIT

$-\%$ uptake on e-filing - PIT

$-\%$ uptake on e-filing - VAT

$\longleftarrow \%$ uptake on e-filing - ToT

Source: Zambia Revenue Authority 


\section{Exhibit 8: Comparison of 2015 Electronic to Manual transactions}

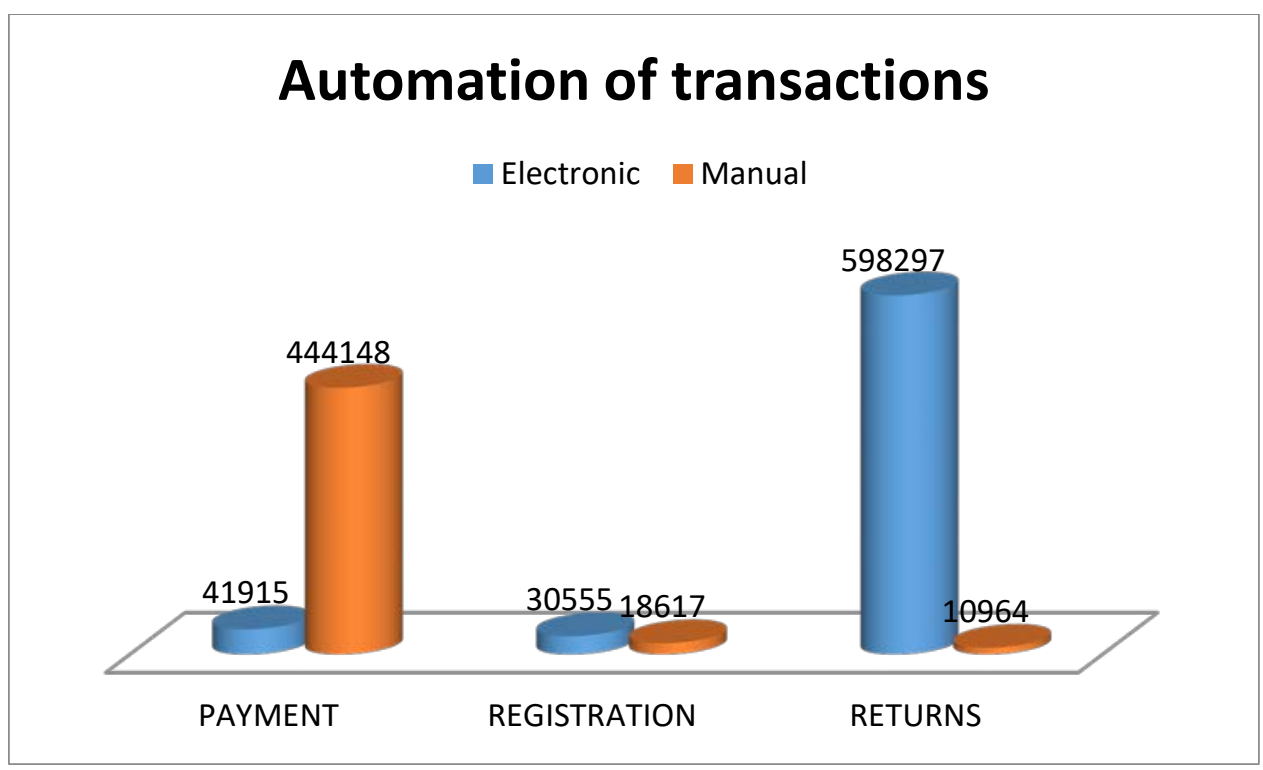

Source: Zambia Revenue Authority 


\section{Exhibit 9: Taxes and Portal Services (eServices)}

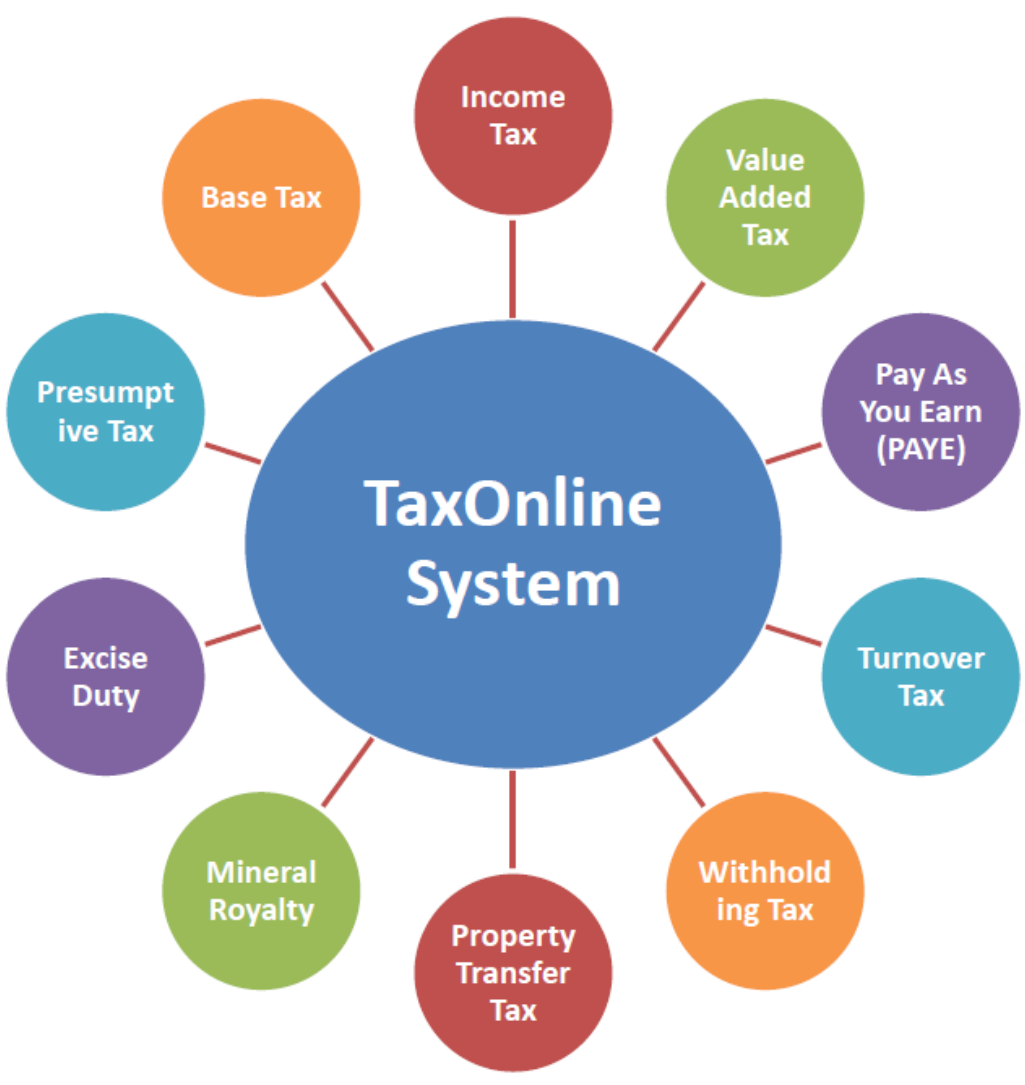

\begin{tabular}{|l|}
\multicolumn{1}{|c}{ Portal Services } \\
\hline E Registration \\
\hline E Amendment \\
\hline E Deregistration / E \\
Reactivation / E \\
Suspension for account \\
and Excise License
\end{tabular}

Source: Zambia Revenue Authority 